\title{
Evaluating the Effectiveness of an Online Medical Laboratory Technician Program
}

\author{
KARA HANSEN-SUCHY
}

OBJECTIVE: The purpose of this study was to analyze the effectiveness of an online medical laboratory technician program in the academic preparation and development of laboratory professionals.

DESIGN: A semi-quantitative comparative research design was used. Several factors were considered in this evaluation. Academic outcomes between online and campus medical laboratory technician (MLT) students was determined by comparing overall and categorical scores on certification exams as well as first time pass rate. Certification exam scores and first time pass rates were also compared to national norms when possible to do so. Demographic data, including age and experience were compared. Additionally, learning styles were assessed to determine if there was a correlation to overall GPA and MLT GPA and if learning styles could be used to predict successful completion of an online Associates of Applied Science.

SETTING: The research was conducted at an academic university located in the mountain west United States.

PARTICIPANTS: Participants consisted of online and campus students enrolled in a Medical Laboratory Technician program that graduated with their Associate of Applied Science degree between the years 20072009. Results of these years were also compared to graduates from 2004-2006 in the same program.

MAIN OUTCOME MEASURES: Certification performance and first time pass rates were the major outcomes measured. Age and experience were correlated. Online learning styles and GPA were also compared to successful degree completion.

RESULTS: The researcher found no significant difference in certification performance with regard to total and categorical scores, and first time pass rates between campus and online MLT students. Online students were slightly older and had more experience working in a laboratory in some capacity. Correlation studies showed significant positive correlation between learning styles, GPA, and successful completion of an Associate of Applied Science degree. When registry scores were compared to the prior cohort of online students, some subcategories scores demonstrated a significant increase using Chi-squared analysis.

CONCLUSIONS: The research demonstrated that the online MLT students studied were as academically prepared as their campus counterparts.

ABBREVIATIONS: ASCP = American Society of Clinical Pathology; MLT = Medical Laboratory Technician; MLS = Medical Laboratory Scientist; MT = Medical Technologist: GPA = grade point average; NAACLS $=$ National Accreditation Agency for Clinical Laboratory Science; LOQ = Learning Orientation Questionnaire

INDEX TERMS: academic performance: program outcomes; online; distance learning; clinical laboratory science.

Clin Lab Sci 2011;24(1):35

Kara Hansen-Suchy, MEd, MT(ASCP)SH, Weber State University, Ogden, UT

Address for Correspondence: Kara Hansen-Suchy, MEd, MT(ASCP)SH, Program Director and Assistant Professor, Weber State University, 3905 University Circle, Ogden, UT 84408-3905, (801) 626-8138, (801) 626-7508 (fax),khansen-suchy@weber.edu 


\section{RESEARCH AND REPORTS}

\section{INTRODUCTION}

Distance education in the United States has grown at a remarkable rate. Historically the number of higher education institutions offering distance or online education has increased from 33 percent in 1994-95 to 66 percent in 2001-02 to approximately 90 percent of 2 and 4 year public post-secondary institutions. ${ }^{1}$ According to Clark and Mayer changing technology, added sophistication, and increased availability of that technology, are reasons for the growth in online learning opportunities. ${ }^{2}$ Today's technology is allowing institutions of higher learning to reach populations in a variety of settings and are opening doors for learners not previously able to participate in a traditional setting. ${ }^{3}$ Part-time students, ages 25 and older, account for the biggest growth in numbers of distance learners, amounting to greater than 40 percent of overall enrollment in higher education. ${ }^{4}$

Some allied health institutions have changed their traditional pedagogical practices and begun to offer laboratory science degrees using web-based technologies in the hopes of attracting additional students. Issues such as administration, student support, training instructors, development of material, delivery methods, and constant changes in technology all present unique challenges for those programs willing to take the online plunge. ${ }^{5}$ There has also been much discussion in recent years on the lack of clinical sites and the unwillingness of laboratory professionals to mentor students in a traditional clinical experience. Through online learning a much larger audience can be reached allowing students to obtain their degree where they work and live.

Several studies have compared distance learning students to their campus counterparts, but there have been few studied in the allied health field and even less in the laboratory arena. The purpose of this study was to determine if there were differences in an online MLT program outcome as compared to their campus counterparts. Several factors were considered in this evaluation. Academic outcomes between online and campus MLT students was determined by comparing overall and categorical scores on certification exams as well as first time pass rate. Certification exam scores and first time pass rates were also compared to national norms when possible to do so. Age and experience demographic data was gathered and evaluated. Additionally, learning styles were assessed to determine if there was a correlation to overall GPA, MLT specific GPA, and successful completion of an Associates of Applied Science.

From an historic perspective, Freeman in 1995 investigated the effectiveness of interactive video conferencing in a small cohort group of 40 students. The researcher found no significant differences in certification scores in comparing delivery methods. ${ }^{6}$ Subsequently, a research study performed in 1999 by Crowley looked at certification pass rates between a campus program and a distance learning program articulating MLTs to MTs. The higher pass rate of the distance learners was attributed to the distance learners having prior education and clinical experience as an MLT. ${ }^{7}$ Then, in 2007 Russell and others reported that MLT distance students performed academically as well as their campus counterparts and postulated that distance learning in MLT can be used to educate laboratory professionals. One limitation of this study was that the majority of the distance learners were MLT to MLS articulated, and the majority of the campus students were not MLTs. Members of this study were also required to have two years of previous college work from an accredited institution to participate in distance learning. ${ }^{8}$

\section{METHODS AND MATERIALS}

The campus program consists of a didactic or lecture component taught concurrently with a student laboratory. The first two MLT courses are open enrollment with the selection process for the degree program occurring after the completion of these courses, and several academic support courses. After completion of thirty-one hours of face-to-face MLT course work and student labs, the campus students perform a two week clinical internship at local hospital affiliates.

Exams for both the campus and online MLT courses must be taken at an authorized testing center or scheduled with an approved and certified proctor. This ensures a secure environment free of distractions and resources that might compromise the integrity of the 


\section{RESEARCH AND REPORTS}

student or the exam. All students are required to present a legitimate photo identification before any exam can be administered.

The online program requires accepted students to have successfully completed three of the five support courses and have at least twenty hours of college credit prior to taking any MLT courses. Research has demonstrated that if students can complete the required support courses prior to taking the MLT courses, the success rate of degree completion is much higher. ${ }^{5}$ The online MLT program requires the student to complete discipline specific clinical experience during the semester that the student takes a particular course. The student is expected to spend a minimum amount of time each week spanning the semester time frame working with a qualified mentor at the clinical facility. The minimum number of hours is based on the course credit but can be increased to meet the needs of the student and facility. For instance, the hematology course is a five credit hour course, thus the student is expected to spend a minimum of five hours per week on average over the sixteen weeks of the semester. This equates to eighty hours in the hematology lab and is equivalent to the student lab time on campus. There is no separate clinical rotation after the completion of the didactic courses for online students. The required course work for both the campus and online program are identical, with the exception of a one credit hour online orientation course used to prepare the student for the online environment. This orientation course is open enrollment and many students will take this course before being accepted into the online program. The vast majority of students accepted into the online MLT program are already employed in the clinical lab as a phlebotomist or specimen processor and viewed by laboratory management as having the potential to become a MLT. These employees are able to be educated, trained, and promoted from within. Rural sites that struggle with attracting laboratory professionals can benefit from the ability to help educate a local native and retain their services as a home grown professional. ${ }^{5}$ These students are likely to stay employed at the facility for years to come. The clinical site can sponsor a student if no employment opportunities are available at the time of training. The clinical site must meet NAACLS standards as a training facility and clinical mentors must also comply with set standards. ${ }^{10}$

Learning styles were determined in a subsection of the online orientation course utilizing the Learning Orientation Questionnaire (LOQ) developed and marketed by Dr. Margaret Martinez and her company The Training Place, $\operatorname{Inc}^{\mathrm{TM}}{ }^{\text {? }}$. The LOQ subdivides students into four different categories of online learners 1) resistant 2) conforming 3) performing and 4) transforming. Resistant learners are just that, while conforming learners prefer simple, safe, low-learner control, structured environments that help learners achieve comfortable, low-risk learning goals in a linear fashion. Performing learners are systematic and use processes and strategies to accomplish tasks. These learners prefer semi-structured environments that provide details, tasks, processes, and creative hands-on interaction; not exploration. Transforming learners deliberately use personal strengths, deep desires, strong emotions, persistent and assertive effort, and sophisticated, abstract or holistic thinking ability and strategies to self-manage learning successfully.

It has been theorized by Martinez that there are learning styles that tend to perform better than others in the online environment. ${ }^{9}$ The student and the orientation instructor receive feedback on the type of learning style the student is most comfortable with and are scored accordingly. Descriptions of the strengths and weaknesses of the different learning styles are presented to the student, with suggestions provided for making modifications to increase success in learning. A subsequent discussion allows the student to assess the positive and negative aspects of their individual learning style and share possible changes in their behavior to enhance online learning.

\section{RESULTS}

The study examined the performance outcome of an online delivered Associate of Applied Science degree versus the traditional classroom at one university in the mountain west. The researcher used a semi-quantitative comparative methodology and gathered data on age, experience, certification scores, and pass rates between campus and online graduates. It is comprised of 75 campus and 32 online graduates taking the certification 


\section{RESEARCH AND REPORTS}

exam between the years 2007-2009. This study also examined the cohort group in the prior three years (2004-2006) consisting of 82 campus and 28 online students.

Outcomes were assessed by comparing categorical and total test scores using an unpaired t-test or Chi-square analysis at $2 \mathrm{p}=0.05$. Campus and online total score and first time pass rates were compared to the national program rates when possible to do so. Figure 1 compares total and categorical scores on the certification exam between campus, online, and national results. No statistical differences were found between the campus, online, and national performance.

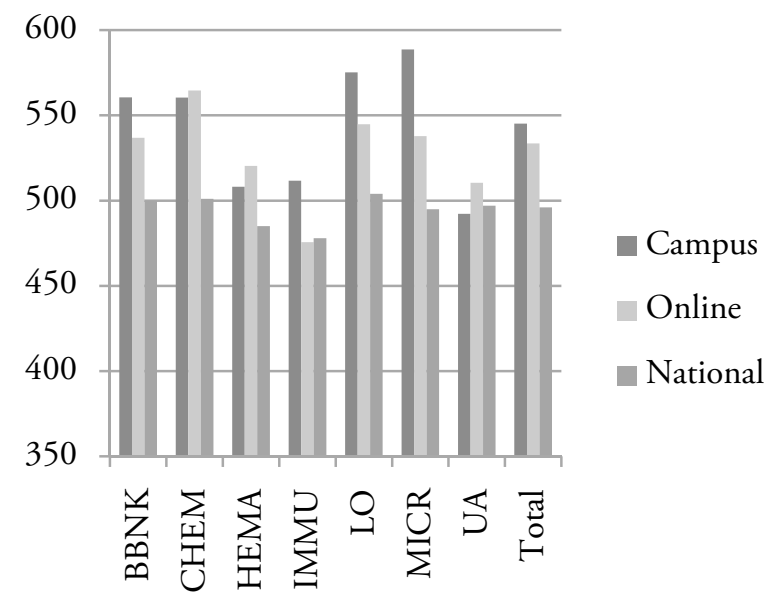

Abbreviations: $\mathrm{BBNK}=$ blood bank; $\mathrm{CHEM}=$ chemistry; HEMA = hematology; $\mathrm{IMMU}=$ immunology; $\mathrm{LO}=$ lab operations; $\mathrm{MICR}=$ microbiology; $\mathrm{UA}=$ urinalysis

Figure 1. Comparison of Campus, Online and National MLT Certification Scores 2007-2009

Figure 2 compares the online group from 2004-2006 to the online group from 2007-2009. Statistical analysis demonstrates a significant improvement in certification scores for the 2007-2009 cohorts using Chi-squared analysis.

First time pass rate, age, and experience as well as certification scores are summarized in Table 1 . Significant differences were observed in age and experience between the campus and online groups, but not in first time pass rates. There was a significant difference between national and program first time pass rate. National data is approximate and estimated from three years (2007-2009) of certification scores and pass rates. It is noted that national data remains very stable from year to year. ${ }^{11}$

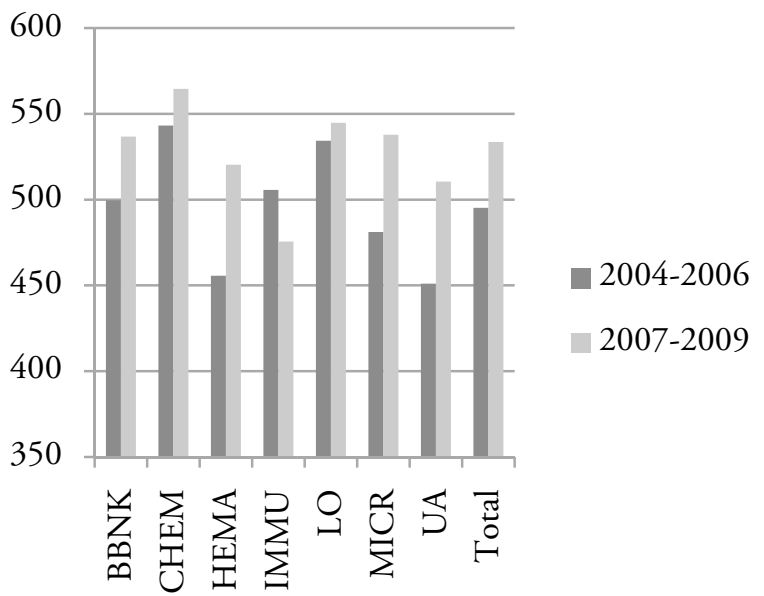

Abbreviations: $\mathrm{BBNK}=$ blood bank; $\mathrm{CHEM}=$ chemistry; HEMA = hematology; $\mathrm{IMMU}=$ immunology; $\mathrm{LO}=$ lab operations; $\mathrm{MICR}=$ microbiology; $\mathrm{UA}=$ urinalysis

Figure 2. Comparison of Online Certification Scores over Time

Table 1. Summary of Comparisons

\begin{tabular}{|c|c|c|c|c|c|c|}
\hline \multicolumn{2}{|c|}{ Certification Scores } & \multicolumn{2}{|c|}{$\begin{array}{c}\text { MLT } \\
2004-06\end{array}$} & \multirow[b]{2}{*}{ Campus } & \multicolumn{2}{|c|}{$\begin{array}{c}\text { MLT } \\
2007-09\end{array}$} \\
\hline & Campus & Online & National & & Online & Nationa \\
\hline $\mathrm{n}=$ & 82 & 28 & 6038 & 75 & 32 & 5682 \\
\hline Total & 546.7 & 495.2 & 479 & 545.2 & 533.6 & 496 \\
\hline $\begin{array}{l}\text { Blood } \\
\text { Bank }\end{array}$ & $563.4^{*}$ & $499.6^{*}$ & & 560.6 & 536.8 & 500 \\
\hline Chemistry & 556.3 & 543.2 & & 560.5 & 564.6 & 501 \\
\hline Hematology & $506.3^{*}$ & $455.6^{*}$ & & 508.2 & 520.31 & 485 \\
\hline Immunology & 534.6 & 505.6 & & 511.7 & 475.6 & 478 \\
\hline $\begin{array}{l}\text { Lab } \\
\text { Operations }\end{array}$ & 601.2 & 534.3 & & 575.2 & 544.8 & 504 \\
\hline Microbiology & y $579.2^{*}$ & $481.1^{*}$ & & 588.7 & 537.8 & 495 \\
\hline Urinalysis & 498.2 & 451 & & 492.2 & 510.5 & 497 \\
\hline $\begin{array}{l}\text { 1st Time } \\
\text { Pass Rate }\end{array}$ & $95.8 \%$ & $88.2 \%$ & $71.7 \% *$ & * $92.0 \%$ & $87.5 \%$ & $77 \% *$ \\
\hline Age in years & $26.9^{*}$ & $32.6^{*}$ & & $25.8^{*}$ & $32.5^{*}$ & \\
\hline $\begin{array}{l}\text { Experience } \\
\text { in years }\end{array}$ & $0.5^{*}$ & $3.5^{*}$ & & $0.5^{*}$ & $3.0^{*}$ & \\
\hline
\end{tabular}

$*_{\text {indicates significance at } \mathrm{p}<0.05}$ 


\section{RESEARCH AND REPORTS}

Table 2. Summary of Learning Style, GPA, and Degree Completion for Online Students

\begin{tabular}{llllrrc}
\hline Learning & LOQ & GPA & \multicolumn{2}{c}{ MLT Number of \% of } & degree \\
\multicolumn{1}{c}{ Style } & Score & & GPA & students & Total & completion \\
Resistant & 3.42 & 1.95 & 2.00 & 4 & $8 \%$ & $0 \%$ \\
Conforming & 4.30 & 2.60 & 2.80 & 10 & $20 \%$ & $50 \%$ \\
Performing & 4.84 & 3.55 & 3.29 & 27 & $56 \%$ & $82 \%$ \\
Transforming & 5.92 & 3.36 & 3.41 & 8 & $16 \%$ & $75 \%$ \\
\hline
\end{tabular}

Learning orientation correlation is outlined in Table 2. The majority of potential online MLT students that participated in the questionnaire scored in the performing category and were more likely to successfully complete their degree. The data presented here does not correlate exactly with the registry data as not all online students taking the LOQ completed their degree. The four online learning styles were broken down and averaged, then compared to GPA, MLT GPA and degree completion. There is a clear correlation between learning style and overall GPA $(r=$ $0.857100074)$ and an even better correlation between LOQ score and MLT GPA $(r=0.926424929)$. Degree completion as related to learning style overall GPA, and MLT GPA has a high correlation $(r=0.85443321)$.

\section{DISCUSSION}

The results of the certification total score, categorical scores, and first time pass rate were analyzed, and found to demonstrate no statistical differences between the campus and online students in the 2007-2009 cohort groups. This is an improvement over the 2004-2006 cohort groups where statistical differences were found in three categorical scores, specifically in blood bank, hematology, and microbiology, with campus students out performing their online counterparts. However, it is important to note that online scores remained above their national counterparts. This change in online performance may be attributed to improvements in web-based technology. Internet speeds have increased and delivery reliability and access has significantly improved over the last few years. ${ }^{12}$ Recorded lectures have been added to more of the online courses. Increased interactivity, communication, and faster instructor response time has been stressed and monitored. Student evaluations have been utilized to note where improvements were needed. Additionally, mentor contact has been increased and encouraged. Weekly suggested activities have been provided to mentors and students must actively reflect on their laboratory experience on a regular basis.

According to statistics our online students are older and more experienced in the laboratory workforce. Exposure to a real laboratory in any capacity is postulated to increase the awareness of how laboratory situations are accessed and handled. Older students from both campus and online settings tend to be more motivated towards career advancements than younger and less focused students. ${ }^{12}$

This analysis indicated that online learning styles can be used to predict future overall GPA and MLT specific GPA. Degree completion is strongly correlated to learning style and could possibly be utilized to council students on their choice of modality for learning and seeking a degree. While transforming learners might perform better in other disciplines, the laboratory sciences are extremely detail oriented and perhaps better suited to the systematic performing learners. Modifications of learning styles is theorized to not occur, however further studies on this, including subsequent testing of graduates pose interesting future studies. Online programs are not for everyone but some students may not have other options, such as a traditional campus face-to-face program. The LOQ also provides our instructors information on the type of learning style of a particular online student and allow the instructor to make modifications of course delivery or support if deemed necessary. It is interesting to note that resistant learners did not complete many semesters in the online environment.

This study showed that online MLT students perform academically as well as their campus counterparts and are as prepared to enter the workforce. These results are very similar to what Russell found for Medical Laboratory Scientists in the 2007 study published in Clinical Laboratory Science. ${ }^{8}$ With the addition of a successful online MLT study; this furthers the claim that an online education is a viable and successful alternative to a traditional face-to-face classroom education. It is hoped that this research will assure all those concerned; from program directors, to lab 


\section{RESEARCH AND REPORTS}

managers, to accrediting agencies, that an online MLT program can meet and even exceed the expectations and outcomes of a traditional program. Further combined studies with multiple programs would be the next logical step in the progression of this research. In the meantime the program will continue to monitor campus and online student performance and use the information to continue to upgrade and improve courses, student support, and program outcomes.

\section{REFERENCES}

1. U.S. Department of Education. Fast Facts. National Center for Education Statistics, 2008.. Available from http://nces.ed.gov/ fastfacts/display.asp?id=80. 1. Accessed 2010 May 20.

2. Clark RC, Mayer RE. E-Learning and the Science of Instruction. San Francisco : Pfeiffer; 2008.

3. Tait AE. Student support in open and distance learning. Open and Distance Learning Today. Routledge, 2005.

4. U.S. Department of Labor. Back to School. Bureau of Labor Statistics, Aug 2007. Available at http://www.bls.gov/spotlight/ 2007/back_to_school/.Accessed 2010 May 20.

5. Hansen-Suchy KF. Development of an orientation class for an online program: A tool to increse student success [Master's Project] Ogden (UT): Weber State University; 2005.
6. Freeman, VS. Delivery methods, learning styles and outcomes for distance medical technology students [dissertation]. Dissertation Abstracts International. 1995; (UMI No. AAT 9536616).

7. Crowley JR, Lauricj GA, Mobley RC, Arnette AH, Shaikh AH, Martin SM. Clinical laboratory technician to clinical laboratory scientists articulation and distance education. Clin Lab Sci 1999;12(1):42-7.

8. Russell BL, Turnbull D, Leibach EK, Pretlow L, Arnette A, Ranne A, et al. Evaluating Distance Learning in Clinical Laboratory Science. Clin Lab Sci 2007; 20(2):106.

9. Martinez M. Learning Orientation Questionnaire. The Training Place, April 2010. Available at: http://www.training place.com/loq/loq.htm. Accessed 2010 May 23.

10. National Accrediting Agency for Clinical Laboratory Sciences. Guide to Accreditation. NAACLS, National Accreditating Agency for Clinical Laboratory Sciences,2003. Available at: http://www.naacls.org/accreditation/newguide_accreditation.as p. Accessed 2010 May 28.

11. American Society for Clinical Pathology. Certification for Program Directors. American Society for Clinical Pathology, 2009. Available from: https:/www.chicago.ascp.org/ Certification/ForProgramDirectors/. Accessed 2010 May 13.

12. Weber State University. Effective Facilitation of Online Courses. WSU Online/Teaching Checklist, 2009. Available at: http://wsuonline.weber.edu/faculty/teaching/Checklist/Checkli stforEffectiveFacilitation.asp. Accessed 2010 May 3. 